\title{
Covid-19: Intensive care consultant has suspension cut short to help fight pandemic
}

\author{
Clare Dyer
}

The BMJ

A consultant in intensive care medicine and anaesthesia who was suspended from the UK medical register has had his 12 month suspension cut short after his NHS trust wrote to the General Medical Council (GMC) without his knowledge, saying that he was needed to help fight the covid-19 pandemic.

The GMC issued new guidance for medical practitioners' tribunals in March on requests to relax or revoke sanctions or interim orders in response to covid-19. The guidance advises that the risk of harm to the public from relaxing or revoking sanctions should be weighed against the risk of harm presented by the coronavirus and the doctor's ability to alleviate it.

It was to this principle that John Bleasdale, a consultant at Sandwell and West Birmingham Hospitals NHS Trust, appealed at a medical practitioners' tribunal, with four months of a 12 month suspension still to run.

Bleasdale was suspended for having been on call for NHS and private hospitals concurrently on 33 occasions-misconduct that had potentially endangered patients, a tribunal found last September. But there was no complaint about his clinical work or competence, and he had held several key hospital positions, including training junior doctors. He had also been a panellist on medical practitioners' tribunals for several years before appearing before one himself.

\section{Public interest}

In March the trust's clinical lead for critical care wrote to the GMC, arguing that "I need every consultant I can get, let alone clinically excellent colleagues like John Bleasdale."

A new hearing was called to consider the possibility of his early return to work. Counsel for the GMC declared that the regulator was "neutral" on the question of ending the suspension early but invited the tribunal to consider whether the public interest in the case had now shifted and might be better served by Bleasdale's return to unrestricted practice after a finding of no current impairment.
Simon Bond, chairing the tribunal, said that it was impressed by the details and extent of Bleasdale's reflections and self-awareness. He had reached full insight and had fully remediated, said Bond, producing an "exemplary" reflective statement. His fitness to practise was found to be no longer impaired, and he can return to practice without restrictions.

The tribunal, said Bond, had to weigh Bleasdale's remediation, his clinical skills, the pressing need for doctors, and the trust's request against "the public interest in upholding public confidence in the profession and maintaining proper professional standards" through enforcing sanctions.

He added, "It concluded that the balance was in favour of Dr Bleasdale's suspension being revoked and allowing him to return to work at the trust as an ICU consultant in order to help address the current public health crisis."

\section{Remediation}

RadcliffesLeBrasseur, a law firm that often represents doctors, commented in a blog post, "It would seem that where the restrictions are imposed on the basis solely of the public interest, without there being any concerns as to the doctor's clinical abilities, there is now a real prospect of having an order of conditions or undertakings amended so as to allow a return to frontline medical practice."

In the case of suspensions, the law firm suggested, interim orders would be more easily overturned than final sanctions. But Bleasdale's case shows that even final sanctions can be lifted during the pandemic if the doctor's remediation is impressive.

The firm added, "Applications for the amendment of restrictions that might have appeared optimistic prior to the coronavirus outbreak might now be more readily entertained if the registrant can, perhaps with the assistance of a letter from the current or potential employer, demonstrate that their services would be of immediate benefit on the front line in the fight against coronavirus." 